\title{
Qualidade física do solo em pastagem adubada e sob pastejo contínuo
}

\author{
Jonez Fidalski(1), Cássio Antonio Tormena(2), Ulysses Cecato(2), Leandro Martins Barbero(2), \\ Simony Marta Bernardo Lugão(1) e Marco Aurélio Teixeira Costa ${ }^{(1)}$
}

(1)Instituto Agronômico do Paraná, Estação Experimental de Paranavaí, Caixa Postal 564, CEP 87701-970 Paranavaí, PR. E-mail: fidalski@iapar.br, lugao@iapar.br, marcocosta@iapar.br (2)Universidade Estadual de Maringá, Avenida Colombo 5.790, CEP 87020-900 Maringá, PR. E-mail: catormena@uem.br, ucecato@uem.br, barberolm@yahoo.com.br

Resumo - O objetivo deste trabalho foi avaliar a qualidade física do solo em pastagens submetidas ao pastejo contínuo. As pastagens foram formadas com capim-coastcross (Cynodon dactylon) consorciado ou não com a leguminosa amendoim forrageiro (Arachis pintoi). A pastagem consorciada recebeu os tratamentos de $0,100 \mathrm{e}$ $200 \mathrm{~kg} \mathrm{ha}^{-1}$ de nitrogênio (N) por ano e a pastagem sem consórcio recebeu $200 \mathrm{~kg} \mathrm{ha}^{-1} \mathrm{de} \mathrm{N}$ por ano, no total de quatro tratamentos. O experimento foi implantado em 2002, em Latossolo Vermelho distrófico, em Paranavaí, PR, em delineamento de blocos ao acaso, com duas repetições. A taxa de lotação animal foi controlada em função da oferta de forragem, entre 2002 e 2007. Em março e novembro de 2007 foram coletadas amostras indeformadas de solo, nas camadas $0-75$ e $75-150 \mathrm{~mm}$ de profundidade, para determinação da densidade, porosidade e capacidade de armazenamento de ar e de água do solo. O pastejo em sistema de lotação contínua, com controle da taxa de lotação animal em função da produção de forragem, não comprometeu a qualidade física do solo. A capacidade de armazenamento de água do solo é um indicador sensível para se avaliarem os efeitos da intensificação da utilização da pastagem sobre a qualidade física do solo.

Termos para indexação: Arachis pintoi, Cynodon dactylon, compactação do solo, nitrogênio, propriedades físicas do solo, taxa de lotação animal.

\section{Soil physical quality in a fertilized pasture under continuous grazing}

Abstract - The objective of this work was to evaluate the physical quality of soil in pastures under continuous grazing. The pastures were established with Bermudagrass coastcross (Cynodon dactylon) intercropped or not with the perennial peanut (Arachis pintoi). The intercropped pasture was fertilized with 0,100 and $200 \mathrm{~kg} \mathrm{ha}^{-1}$ nitrogen (N) per year and the single-cropped pasture was fertilized with $200 \mathrm{~kg} \mathrm{ha}^{-1} \mathrm{~N}$ per year, totaling four treatments. The experiment was established in 2002 in a Haplorthox (Rhodic Ferralsol) in Paranavaí, northwestern of Paraná, Brazil, using a randomized complete block design, with two replications. Between 2002 and 2007 the stocking rate was based on forage offer level. In March and November 2007, undisturbed soil samples were collected from 0-75 and 75-150 mm depths for the evaluation of soil bulk density, soil porosity, and soil air and water storage capacity. Continuous grazing with stocking rates controlled as a function of the pasture production did not damage the soil physical quality. The soil water storage capacity is a sensitive indicator to assess the effects of stocking rate intensification on soil physical quality.

Index terms: Arachis pintoi, Cynodon dactylon, soil compaction, nitrogen, soil physical properties, stocking rate.

\section{Introdução}

A redução da produtividade das pastagens tem sido relacionada ao manejo inadequado da fertilidade do solo, das espécies forrageiras exploradas e da taxa de lotação animal, que podem comprometer a qualidade física do solo. A adubação química do solo e o manejo das espécies forrageiras exploradas têm contribuído para melhorar a produtividade da pastagem (Oliveira et al., 2003; Corrêa et al., 2007). Entre os nutrientes, o nitrogênio é o que mais contribui para o aumento da produtividade das pastagens, principalmente quando não há restrição dos demais nutrientes necessários ao desenvolvimento das plantas (Lugão et al., 2003). O consórcio de gramíneas e leguminosas representa uma alternativa para a recuperação ou manutenção de solos de baixa fertilidade (Silva \& Saliba, 2007) e contribui para a melhoria da qualidade da forragem oferecida aos animais (Paciullo et al., 2003). 
A melhoria da fertilidade do solo aumenta a produtividade das pastagens e permite intensificar a sua utilização com maior da taxa de lotação animal (Lugão et al., 2003). A pressão do casco dos animais sobre o solo pode comprometer a qualidade física na camada superficial, em razão do aumento da densidade do solo e da redução da porosidade (Twerdoff et al., 1999; Imhoff et al., 2000; Giarola et al., 2007). A densidade e a porosidade do solo são as propriedades físicas mais amplamente utilizadas na quantificação da qualidade física do solo, em pastagem sob pastejo, a qual é mais afetada nos primeiros $150 \mathrm{~mm}$ de profundidade (Greenwood \& Mckenzie, 2001; Lanzanova et al., 2007).

O aumento da pressão de pastejo, relação entre o peso animal e a massa de forragem disponível [ $\mathrm{kg}_{\text {(animal) }} \mathrm{kg}^{-1}$ (massa seca de forragem) $\left.\mathrm{dia}^{-1}\right]$, em conseqüência do aumento da taxa de lotação animal em pastagens de baixa produtividade, compromete a qualidade física do solo, pois resulta em maior carga de animais sobre o solo (Silva et al., 2003), independentemente do sistema de produção (pastejo rotacionado, contínuo e integração lavoura-pecuária), conforme Leão et al. (2006), Lanzanova et al. (2007) e Marchão et al. (2007).

O consórcio da gramínea coastcross (Cynodon dactylon) com a leguminosa amendoim forrageiro (Arachis pintoi) concentra $63 \%$ das raízes na profundidade 0-150 mm (Ribeiro, 2007). De acordo com esse autor, a adubação nitrogenada aumenta os teores de carboidratos não estruturais das raízes das forrageiras consorciadas. A máxima atividade biológica, medida pela liberação de nitrogênio disponível às plantas via mineralização da matéria orgânica, ocorre quando a saturação relativa do solo é de $66 \%$ ou, complementarmente, quando $34 \%$ do seu espaço poroso de solo é ocupado com ar (Skopp et al., 1990). Com base nessas relações, Reynolds et al. (2002) propuseram os indicadores armazenamento de água e capacidade de armazenamento de ar do solo, com valores ideais de 0,66 e 0,34 (adimensional; v/v), respectivamente, que caracterizam como solos de boa qualidade para armazenar água e ar, quando o espaço poroso na capacidade de campo apresentar 2/3 com água e $1 / 3 \mathrm{com}$ ar.

$\mathrm{O}$ efeito do pisoteio dos animais sobre o solo é potencializado, quando o pastejo é realizado em solos com umidade elevada e com baixa cobertura vegetal, o que evidencia a importância do controle das taxas de lotação animal, em relação à quantidade de pastagem produzida e à manutenção de cobertura vegetal adequada sobre os solos, a fim de mitigar esse efeito do pisoteio sobre a qualidade física dos solos (Silva et al., 2003; Sarmento et al., 2008).

O objetivo do presente trabalho foi avaliar a qualidade física de um Latossolo Vermelho distrófico, em pastagem sob pastejo contínuo de gramínea coastcross (Cynodon dactylon) consorciado com amendoim forrageiro (Arachis pintoi), com taxa de lotação animal controlada em função da oferta de forragem proporcionada pela adubação nitrogenada.

\section{Material e Métodos}

O experimento foi conduzido na Estação Experimental do Instituto Agronômico do Paraná (Iapar), em Paranavaí, no Noroeste do Paraná $\left(23^{\circ} 5^{\prime} \mathrm{S}, 52^{\circ} 26^{\prime} \mathrm{W}\right.$ e altitude de $460 \mathrm{~m}$ ). O clima na região é subtropical (Cfa), com tendência de concentração de chuvas entre novembro e março, porém sem estação seca definida. A taxa de precipitação média anual é de $1.500 \mathrm{~mm}$. O solo é Latossolo Vermelho distrófico textura arenosa média A moderado relevo suave-ondulado, com declive de $5 \mathrm{~cm} \mathrm{~m}^{-1}$ (Embrapa, 2006), desenvolvido a partir do arenito da Formação Caiuá. A textura do solo na camada $0-150 \mathrm{~mm}$ de profundidade é arenosa (Embrapa, 2006), com 892, 10 e $98 \mathrm{~g} \mathrm{~kg}^{-1}$ de areia, silte e argila, respectivamente.

A área experimental era de 5,4 ha e tinha sido explorada com Brachiaria humidicola (Rendle) Schweick, pastejada por bovinos em sistema de lotação contínua até 1997, e o solo apresentava baixa fertilidade (Tabela 1). No período 1998-2000, essa pastagem foi reformada por meio de plantio direto, no sistema integração lavoura-pecuária (aveia/soja-aveia/ milho-aveia/soja-aveia), que elevou a fertilidade do

Tabela 1. Características químicas do solo à profundidade 0-20 cm, antes da reforma da pastagem (1998), após a rotação (2000), e a média dos tratamentos da pastagem de coastcross e amendoim forrageiro com e sem adubação nitrogenada (2006).

\begin{tabular}{ccccccccc}
\hline Ano & $\begin{array}{c}\mathrm{P} \\
\left(\mathrm{mg} \mathrm{dm}^{-3}\right)\end{array}$ & $\begin{array}{c}\mathrm{C} \\
\left(\mathrm{g} \mathrm{dm}^{-3}\right)\end{array}$ & $\begin{array}{c}\mathrm{pH} \\
\mathrm{CaCL}_{2}\end{array}$ & $\begin{array}{c}\mathrm{Al}^{3+} \\
-\end{array}$ & $\begin{array}{c}\mathrm{Ca}^{2+} \\
\left.\mathrm{cmol}_{\mathrm{c}} \mathrm{dm}^{-3}\right)\end{array}$ & $\begin{array}{c}\mathrm{K}^{+} \\
\text {------- }\end{array}$ & $\begin{array}{c}\mathrm{V} \\
(\%)\end{array}$ \\
\hline 1998 & 4,8 & 9,0 & 4,8 & 0,00 & 1,30 & 0,80 & 0,44 & 45 \\
2000 & 10,8 & 9,9 & 4,8 & 0,07 & 1,53 & 0,90 & 0,21 & 44 \\
2006 & 11,0 & 7,7 & 5,0 & 0,09 & 1,28 & 0,95 & 0,23 & 47 \\
\hline
\end{tabular}


solo (Tabela 1). Em novembro de 2000, plantou-se a gramínea coastcross (Cynodon dactylon Pers.), com mudas distribuídas em covas espaçadas em $80 \mathrm{~cm}$. Cerca de 30 dias após o plantio da gramínea, $10 \mathrm{~kg} \mathrm{ha}^{-1}$ de sementes de amendoim forrageiro (Arachis pintoi Krap. \& Greg.) cultivar Amarillo foram infectadas com estirpe específica de Rhizobium e semeadas em sistema de plantio direto, com espaçamento de $70 \mathrm{~cm}$ nas entrelinhas. Na implantação da pastagem, não houve necessidade da correção da acidez do solo; somente adubações com $\mathrm{P}$ e $\mathrm{K}$, definidas a partir de resultados de análises químicas de solo (Tabela 1). A pastagem consorciada de coastcross e amendoim forrageiro foi formada em dezembro de 2001.

$\mathrm{O}$ delineamento experimental utilizado foi o de blocos ao acaso, com duas repetições. Cada parcela experimental correspondeu a um piquete retangular com aproximadamente $6.600 \mathrm{~m}^{2}$, disposto com o maior comprimento perpendicular ao declive do terreno. Os tratamentos avaliados foram: consórcio de coastcross e amendoim forrageiro, sem adubação nitrogenada (CA0); consórcio de coastcross e amendoim forrageiro, com $100 \mathrm{~kg} \mathrm{ha}^{-1}$ de $\mathrm{N}$ anualmente (CA100); consórcio de coastcross e amendoim forrageiro, com $200 \mathrm{~kg} \mathrm{ha}^{-1}$ de $\mathrm{N}$ anualmente (CA200); e coastcross, com $200 \mathrm{~kg} \mathrm{ha}^{-1}$ de $\mathrm{N}$ anualmente (C200). A aplicação do fertilizante nitrogenado foi realizada no período de maior precipitação (primavera e verão). As doses foram parceladas anualmente, entre duas e quatro aplicações, distribuídas a lanço.

Durante o período experimental, foram realizadas adubações com $\mathrm{P}$ e $\mathrm{K}$, para manter os teores em torno de $10 \mathrm{mg} \mathrm{dm}^{-3}$ de P e de 0,20 $\mathrm{cmol}_{\mathrm{c}} \mathrm{dm}^{-3}$ de K (Tabela 1). Em dezembro de 2005, foi realizada uma calagem superficial, para elevar a saturação por bases a $70 \%$, que é eficiente nesses solos (Fidalski \& Tormena, 2005; Fidalski \& Auler, 2008).

No período de 2002 a 2007, a área experimental foi pastejada com lotação contínua e carga animal variável com novilhas cruzadas (Zebu x Europeu), com três animais testadores com peso médio inicial de aproximadamente $170 \mathrm{~kg}$. O ajuste da taxa de lotação animal foi realizado pela técnica "put-and-take", proposta por Mott \& Lucas (1952), com a finalidade de garantir a oferta de $6,6 \mathrm{~kg}$ de forragem por $100 \mathrm{~kg}$ de peso vivo animal. A adubação nitrogenada e a consorciação do coastcross com amendoim forrageiro proporcionaram taxas de acúmulo de forragem distintas entre os tratamentos que, por sua vez, definiram diferentes taxas de lotação animal no decorrer dos anos (Tabela 2).

A amostragem para a avaliação da qualidade física do solo foi realizada em duas épocas - março e novembro de 2007 - e nas camadas do solo 0-75 e 75-150 mm de profundidade. Foram coletadas três subamostras, em cada parcela experimental (uma em cada $1 / 3$ do piquete), com anéis volumétricos de aço inox com $5 \mathrm{~cm}$ de altura e diâmetro. As amostras de solo foram envoltas em papel alumínio e mantidas sob refrigeração, até o momento das determinações. Em laboratório, as amostras foram saturadas em bandejas, com uma lâmina de água até dois terços da altura dos anéis. A obtenção do conteúdo de água, nos potenciais matriciais de -1 e $-6 \mathrm{kPa}$, foi realizada com uso de uma mesa de tensão; enquanto no potencial de -10 kPa, utilizaram-se câmaras de Richards (Embrapa, 1997). Em seguida, as amostras foram secadas em estufa a $105^{\circ} \mathrm{C}$ por 48 horas e pesadas para a determinação da massa de sólidos e cálculo da densidade do solo.

A porosidade total do solo $(\mathrm{Pt})$ foi estimada pela equação: $\mathrm{Pt}=1$ - (densidade do solo/densidade de partículas do solo), tendo-se utilizado o valor médio de 2,62 $\mathrm{Mg} \mathrm{m}^{-3}$ para a densidade de partículas do solo (Fidalski et al., 2007). A macroporosidade foi estimada pela diferença entre o conteúdo de água do solo saturado e o conteúdo de água no potencial matricial de $-6 \mathrm{kPa}$; a microporosidade foi estimada como o conteúdo de água do solo retido no potencial matricial de $-6 \mathrm{kPa}$ (Embrapa, 1997).

O indicador de capacidade de armazenamento de água do solo (adimensional) foi calculado por meio das relações entre o conteúdo de água do solo, retido no potencial matricial equivalente à capacidade de campo (CC), determinada no potencial matricial de $-10 \mathrm{kPa}$, com a porosidade total do solo $(\mathrm{Pt})$, conforme

Tabela 2. Indicadores médios de produção animal e de forragem, em pastagem de coastcross (C), amendoim forrageiro (A) e adubação nitrogenada $\left(0,100,200 \mathrm{~kg} \mathrm{ha}^{-1}\right.$ de $\mathrm{N}$ ), sob lotação contínua de novilhas, no período de janeiro/2002 a junho/2007.

\begin{tabular}{lrrrr}
\hline Indicador de produção & CA0 & CA100 & CA200 & C200 \\
\hline Taxa de lotação animal $\left(\mathrm{UA} \mathrm{ha}^{-1}\right)^{(1)}$ & 3,75 & 4,16 & 4,79 & 4,75 \\
Massa de forragem $\left(\mathrm{kg} \mathrm{ha}^{-1}\right)$ & 3.060 & 2.518 & 3.183 & 3.029 \\
Acúmulo de forragem $\left(\mathrm{kg} \mathrm{ha}^{-1}\right.$ por dia) & 54 & 56 & 62 & 63 \\
\hline (1)Unidade animal $(1 \mathrm{UA}=450 \mathrm{~kg}$ de peso vivo). & & &
\end{tabular}

Pesq. agropec. bras., Brasília, v.43, n.11, p.1583-1590, nov. 2008 
descrito em Reynolds et al. (2002): capacidade de armazenamento de água do solo $=\mathrm{CC} / \mathrm{Pt}$.

$\mathrm{O}$ indicador capacidade de armazenamento de ar do solo (adimensional) foi calculado pelo quociente entre o volume de poros drenados entre o solo saturado e o potencial matricial de $-10 \mathrm{kPa}(\mathrm{CAt})$, em relação à porosidade total do solo $(\mathrm{Pt})$, conforme descrito por Reynolds et al. (2002): capacidade de armazenamento de ar do solo $=$ CAt $/$ Pt.

Outros indicadores de qualidade física do solo foram calculados conforme proposição de Reynolds et al. (2002): porosidadeno domínio dos macroporos, definida como o volume de poros drenados entre a saturação e o potencial mátrico de $-1 \mathrm{kPa}$, equivalente aos poros com diâmetro superiores a $300 \mu \mathrm{m}$; porosidade no domínio da matriz do solo, definida pelo volume de poros com água no potencial mátrico de $-10 \mathrm{kPa}$, equivalente aos poros com diâmetro inferiores a $300 \mu \mathrm{m}$; e a capacidade de aeração da matriz do solo, definida como o volume de poros drenados entre o potencial matricial de $-1 \mathrm{kPa}$ e solo seco em estufa a $105^{\circ} \mathrm{C}$. Na Figura 1, é ilustrada a distribuição dos poros, em razão dos indicadores tradicionais (densidade do solo, macroporosidade, microporosidade e porosidade total) e os indicadores propostos por Reynolds et al. (2002).
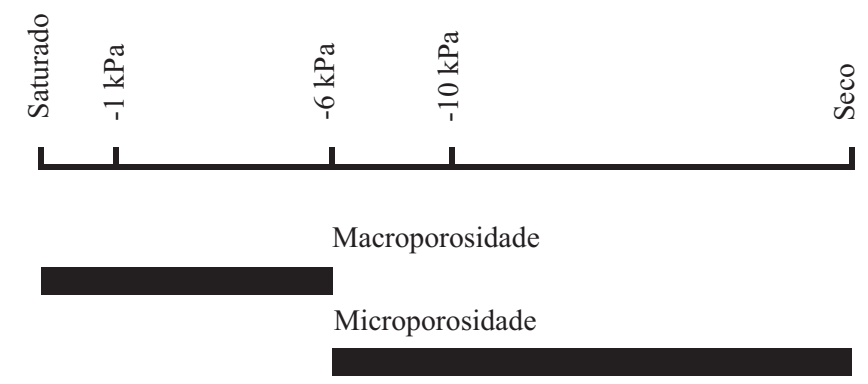

Porosidade no domínio dos macroporos

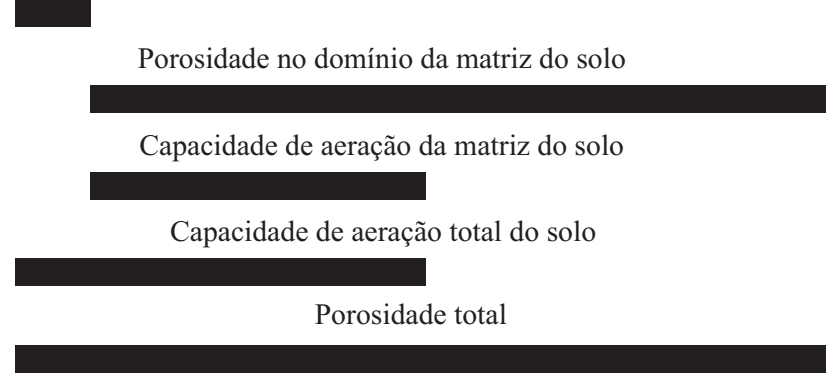

Figura 1. Indicadores de qualidade física do solo, relativos à porosidade entre o solo saturado e seco: os tradicionais macroporosidade, microporosidade e porosidade total - e os propostos por Reynolds et al. (2002).
Os indicadores de qualidade física do solo (médias das três subamostras por parcela experimental) foram submetidas às análises de variância pelo modelo matemático de blocos ao acaso, no esquema de parcelas sub-subdivididas (no tempo), e a comparação de médias (Teste F; $<<0,05$ ) foi feita pelo teste de Tukey, a 5\% de probabilidade (Banzatto \& Kronka, 2006). Foram considerados: na parcela, quatro tratamentos (CA, CA100, CA200 e C200); na subparcela, duas camadas de solo (0-75 e 75-150 $\mathrm{mm}$ de profundidade); e na subsubparcela, duas épocas de amostragem de solo (março e novembro de 2007).

\section{Resultados e Discussão}

O efeito dos tratamentos (CA, CA100, CA200 e C200), camadas de solo (0-75 e 75-150 $\mathrm{mm}$ de profundidade) e época de amostragem (março e novembro) foram independentes quanto aos indicadores de qualidade física do solo $(p>0,05)$. Isto significa que os indicadores de qualidade física do solo não foram dependentes das camadas e das épocas de amostragem de solo.

Não houve efeito dos tratamentos (CA, CA100, CA200 e C200) quanto aos indicadores: densidade do solo, macroporosidade, microporosidade e porosidade total (Tabela 3), resultante das taxas de lotação animal médias, praticadas nos diferentes tratamentos durante 2002-2007 (Tabela 2). Os valores de densidade do solo foram semelhantes aos encontrados por Fidalski et al. (2007) em um Argissolo Vermelho distrófico, da mesma região, cultivado com grama batatais ou mato-grosso (Paspalum notatum), nas entrelinhas de citros, sob o rodado das máquinas agrícolas e entrerrodado, respectivamente, 1,68 e $1,63 \mathrm{Mg} \mathrm{m}^{-3}$. A macroporosidade observada nos diferentes tratamentos foi igual ou superior ao limite mínimo de $0,10 \mathrm{~m}^{3} \mathrm{~m}^{-3}$ (Tabela 3 ), ideal para que ocorra a adequada difusão de oxigênio no solo, para o bom desenvolvimento das plantas (Grable \& Siemer, 1968).

A porosidade no domínio dos macroporos e da matriz do solo apresentou o mesmo comportamento da porosidade total e não se diferenciou entre os tratamentos avaliados (Tabela 3). Reynolds et al. (2002) verificaram maior porosidade no domínio dos macroporos e da matriz do solo, em solos canadenses com diferentes classes texturais sob floresta nativa, em comparação aos sistemas plantio direto e convencional, 
atribuída aos maiores teores de C orgânico, maior extensão de raízes e biota sob floresta nativa. Em solo arenoso similar ao do presente trabalho, Fidalski et al. (2007) verificaram que a porosidade no domínio dos macroporos aumentou, sob o rodado das entrelinhas de citros com o amendoim forrageiro, mas diminuiu com a vegetação espontânea, sob o entrerrodado da entrelinha de citros, o que comprometeu a retenção de água no solo, em comparação com a gramínea batatais ou mato-grosso (Paspalum notatum), que produziu maior biomassa. O manejo dos tratamentos CA, CA100, CA200 e C200, com taxa de lotação animal ajustada por meio da adubação nitrogenada, manteve a massa de forragem e o teor de C orgânico, sem alterar significativamente a porosidade no domínio dos macroporos e da matriz do solo (Tabelas 1, 2 e 3).

A capacidade de armazenamento de ar do solo foi menor no tratamento CA200, emrelação aos tratamentos CA0 e CA100, os quais não se diferenciaram do tratamento C200 (Tabela 3). Contudo, os valores desses indicadores encontram-se superiores ao limite mínimo de $0,10-0,15 \mathrm{~m}^{3} \mathrm{~m}^{-3}$, conforme Reynolds et al. (2002). Os indicadores de capacidade de aeração, no domínio dos macroporos e na matriz do solo, diferenciaram os tratamentos (Tabela 3). Esses resultados evidenciam a maior distinção entre os tratamentos por meio da capacidade de aeração do solo, determinada no potencial matricial $-10 \mathrm{kPa}$, proposto por Reynolds et al. (2002), do que a macroporosidade no potencial matricial de $-6 \mathrm{kPa}$.
As maiores taxas de lotação animal, proporcionadas pelos tratamentos com maior dose de N (CA200 e C200), resultaram em maior conteúdo de água retida no solo à capacidade de campo, em relação ao tratamento CA100 (Tabela 3). A menor capacidade de retenção de água, no tratamento CA100, foi influenciada pela menor cobertura do solo pela massa de forragem (Tabela 2), o que concorda com os resultados de Silva et al. (2003). O efeito da maior retenção de água à capacidade de campo, nos tratamentos com as maiores doses de N (200 kg ha $\left.{ }^{-1}\right)$, é positivo, tendo-se em vista que a velocidade de crescimento da espécie forrageira, nesses tratamentos, foi maior, conforme verificado pelo maior acúmulo de forragem (Tabela 2).

Os indicadores capacidade de armazenamento de água e ar do solo revelaram que o tratamento C200 apresentou maior capacidade de reter água no solo $(0,49)$, tendo-se aproximado mais do índice ideal de 0,64 (Reynolds et al., 2002) do que os tratamentos C0 e C100, que não se diferenciaram do tratamento C200 (Tabela 3). Esses resultados confirmam que o ajuste da taxa de lotação animal, por meio da massa de forragem produzida com diferentes doses de $\mathrm{N}(\mathrm{C} 0, \mathrm{C} 100$ e C200), não comprometeu a qualidade física do solo com a máxima dose de $\mathrm{N}$ (Tabelas 2 e 3).

Segundo Skopp et al. (1990), a máxima produtividade, decorrente do aproveitamento do $\mathrm{N}$ mineralizado a partir da matéria orgânica, ocorre quando $66 \%$ dos poros estão preenchidos com água, e $34 \%$ são ocupados com ar. Assim, o tratamento CA200

Tabela 3. Valores médios e coeficientes de variação (CV) dos indicadores de qualidade física do solo, nas camadas $0-75$ e 75-150 mm de profundidade, avaliados em março e novembro de 2007, sob pastagem de coastcross (C) e amendoim forrageiro (A), com adubação nitrogenada $\left(0,100,200 \mathrm{~kg} \mathrm{ha}^{-1} \mathrm{de} \mathrm{N}\right)$, sob lotação contínua de novilhas ${ }^{(1)}$.

\begin{tabular}{|c|c|c|c|c|c|c|}
\hline \multirow[t]{2}{*}{ Indicador $^{(2)}$} & \multicolumn{4}{|c|}{ Tratamentos } & \multirow[t]{2}{*}{ Média } & \multirow{2}{*}{$\begin{array}{l}\text { CV } \\
(\%)\end{array}$} \\
\hline & $\mathrm{CA} 0$ & CA100 & CA200 & $\mathrm{C} 200$ & & \\
\hline Densidade do solo $\left(\mathrm{Mg} \mathrm{m}^{-3}\right)$ & $1,64 \mathrm{a}$ & $1,68 \mathrm{a}$ & $1,68 \mathrm{a}$ & $1,63 \mathrm{a}$ & 1,66 & 1,64 \\
\hline Macroporosidade $\left(\mathrm{m}^{3} \mathrm{~m}^{-3}\right)$ & $0,11 \mathrm{a}$ & $0,11 \mathrm{a}$ & $0,10 \mathrm{a}$ & $0,11 \mathrm{a}$ & 0,11 & 16,33 \\
\hline Microporosidade $\left(\mathrm{m}^{3} \mathrm{~m}^{-3}\right)$ & $0,28 \mathrm{a}$ & $0,26 \mathrm{a}$ & $0,27 \mathrm{a}$ & $0,28 \mathrm{a}$ & 0,27 & 3,25 \\
\hline Porosidade total $\left(\mathrm{m}^{3} \mathrm{~m}^{-3}\right)$ & $0,39 a$ & $0,37 \mathrm{a}$ & $0,37 \mathrm{a}$ & $0,39 \mathrm{a}$ & 0,38 & 4,61 \\
\hline PDMacro $\left(\mathrm{m}^{3} \mathrm{~m}^{-3}\right)$ & $0,03 a$ & $0,03 \mathrm{a}$ & $0,03 \mathrm{a}$ & $0,03 \mathrm{a}$ & 0,03 & 17,10 \\
\hline PDMatriz $\left(\mathrm{m}^{3} \mathrm{~m}^{-3}\right)$ & $0,36 \mathrm{a}$ & $0,34 \mathrm{a}$ & $0,34 \mathrm{a}$ & $0,36 \mathrm{a}$ & 0,35 & 4,33 \\
\hline CAMatriz $\left(\mathrm{m}^{3} \mathrm{~m}^{-3}\right)$ & $0,19 \mathrm{a}$ & $0,19 \mathrm{a}$ & $0,16 b$ & $0,17 \mathrm{ab}$ & 0,18 & 5,79 \\
\hline $\operatorname{CAt}\left(\mathrm{m}^{3} \mathrm{~m}^{-3}\right)$ & $0,22 \mathrm{a}$ & $0,22 \mathrm{a}$ & $0,19 b$ & $0,21 \mathrm{ab}$ & 0,21 & 5,04 \\
\hline $\mathrm{CC}\left(\mathrm{m}^{3} \mathrm{~m}^{-3}\right)$ & $0,17 \mathrm{ab}$ & $0,15 b$ & $0,18 \mathrm{a}$ & $0,18 \mathrm{a}$ & 0,17 & 7,00 \\
\hline $\mathrm{CC} / \mathrm{Pt}$ & $0,44 \mathrm{~b}$ & $0,41 b$ & $0,49 \mathrm{a}$ & $0,46 a b$ & 0,45 & 4,86 \\
\hline $\mathrm{CAt} / \mathrm{Pt}$ & $0,56 \mathrm{a}$ & $0,59 \mathrm{a}$ & $0,51 \mathrm{~b}$ & $0,54 \mathrm{ab}$ & 0,55 & 4,86 \\
\hline
\end{tabular}

${ }^{(1)}$ Médias seguidas de letras iguais, na linha, não diferem entre si, a 5\% de probabilidade pelo teste Tukey. ${ }^{(2)}$ PDMacro, porosidade no domínio dos macroporos; PDMatriz, porosidade no domínio da matriz do solo; CAMatriz, capacidade de aeração da matriz do solo; CAt, capacidade de aeração total do solo; CC, conteúdo de água retido à capacidade de campo; CC/Pt, capacidade de armazenamento de água do solo, adimensional; e CAt/Pt, capacidade de armazenamento de ar do solo, adimensional. 
foi o que mais se aproximou desta condição, o que evidencia a importância da maior retenção de água, principalmente em solos de textura arenosa, como é o caso do Latossolo Vermelho distrófico que representa, com o Argissolo Vermelho distrófico, a maior parte dos cerca de três milhões de hectares no Noroeste do Paraná, dos quais $70 \%$ se constitui em uma das principais regiões de pastagem do Estado.

Houve diferenças entre as camadas de solo $(\mathrm{p}<0,05)$, e foi observada menor densidade do solo e maior microporosidade e capacidade de armazenamento de água do solo na camada 0-75 mm, em comparação à de 75-150 $\mathrm{mm}$ de profundidade (Tabela 4). Esses resultados caracterizam o maior armazenamento de água na camada superficial, em razão dos maiores teores de C orgânico (Tabela 1), constatados também por Fidalski \& Tormena (2007) e Machado et al. (2008), em solos similares mantidos com gramínea. A manutenção da cobertura vegetal (Tabela 2) minimizou o efeito do pisoteio animal sobre o solo cuja degradação tem sido relacionada à redução dessa cobertura (Muller et al., 2001). Contrariamente, Sarmento et al. (2008) verificaram maior densidade do solo na camada superficial, diferentemente do presente estudo. Tais diferenças são atribuídas ao hábito de crescimento das espécies, pelo qual a coastcross (estolonífera) manteve o solo permanentemente vegetado, no presente trabalho, enquanto no de Sarmento et al. (2008) a utilização do Panicum maximum (cespitosa) resultou em áreas de pisoteio entre as touceiras.
Os tratamentos se diferenciaram em relação aos indicadores de qualidade física do solo, medidos nas épocas de avaliação de março e novembro $(p>0,05)$, à exceção do conteúdo de água retido à capacidade de campo (Tabela 4). Twerdoff et al. (1999) também verificaram variação temporal da densidade do solo e do conteúdo de água no solo, em conseqüência da taxa de lotação animal. A maior densidade do solo, verificada em março (Tabela 4), foi atribuída à maior taxa de lotação animal, em razão da maior oferta de forragem que precedeu essa época de amostragem, em período de maior ocorrência de chuvas na região. Esse aumento da densidade do solo não comprometeu a porosidade nem a capacidade de aeração e proporcionou índices mínimos de 0,10 e $0,15 \mathrm{~m}^{3} \mathrm{~m}^{-3}$ (Reynolds et al., 2002).

O manejo da taxa de lotação animal, por meio do aumento de massa e do acúmulo da forragem com adubação nitrogenada, não comprometeu a qualidade física do solo avaliada pelos indicadores: densidade do solo, macroporosidade, microporosidade e porosidade total, que foram sensíveis para diferenciar camadas e épocas de amostragem de solo (Tabelas 2, 3 e 4). O indicador capacidade de armazenamento de água do solo apresentou maior sensibilidadepara diferenciaros tratamentos, camadas e épocas de amostragem de solo. Esses resultados indicam o potencial de utilização dos indicadores de qualidade física do solo propostos por Reynolds et al. (2002), com baixo custo e equipamentos básicos de laboratório de física do solo (mesa de tensão), se for utilizado o potencial matricial de $-8 \mathrm{kPa}$ (Fidalski et al., 2007).

Tabela 4. Valores médios e coeficientes de variação (CV) dos indicadores de qualidade física do solo, nas camadas 0-75 e 75-150 mm de profundidade, e épocas de amostragem (março e novembro de 2007), em pastagem de coastcross e amendoim forrageiro, com adubação nitrogenada $\left(0,100,200 \mathrm{~kg} \mathrm{ha}^{-1} \mathrm{de} \mathrm{N}\right)$, sob lotação contínua de novilhas ${ }^{(1)}$.

\begin{tabular}{|c|c|c|c|c|c|c|c|c|}
\hline \multirow[t]{2}{*}{ Indicador $^{(2)}$} & \multicolumn{2}{|c|}{ Camada (mm) } & \multirow[t]{2}{*}{ Média } & \multirow{2}{*}{$\begin{array}{l}\text { CV } \\
(\%)\end{array}$} & \multicolumn{2}{|c|}{ Época } & \multirow[t]{2}{*}{ Média } & \multirow{2}{*}{$\begin{array}{l}\text { CV } \\
(\%)\end{array}$} \\
\hline & $0-75$ & $75-150$ & & & Mar. & Nov. & & \\
\hline Densidade do solo $\left(\mathrm{Mg} \mathrm{m}^{-3}\right)$ & $1,61 b$ & $1,70 \mathrm{a}$ & 1,66 & 2,25 & $1,67 \mathrm{a}$ & $1,64 b$ & 1,66 & 2,03 \\
\hline Macroporosidade $\left(\mathrm{m}^{3} \mathrm{~m}^{-3}\right)$ & $0,10 \mathrm{a}$ & $0,12 \mathrm{a}$ & 0,11 & 24,72 & $0,12 \mathrm{a}$ & $0,09 \mathrm{~b}$ & 0,11 & 17,87 \\
\hline Microporosidade $\left(\mathrm{m}^{3} \mathrm{~m}^{-3}\right)$ & $0,29 a$ & $0,26 b$ & 0,28 & 2,83 & $0,24 b$ & $0,30 \mathrm{a}$ & 0,27 & 4,91 \\
\hline Porosidade total $\left(\mathrm{m}^{3} \mathrm{~m}^{-3}\right)$ & $0,39 a$ & $0,37 \mathrm{a}$ & 0,38 & 6,68 & $0,36 \mathrm{~b}$ & $0,39 a$ & 0,38 & 3,90 \\
\hline PDMacro $\left(\mathrm{m}^{3} \mathrm{~m}^{-3}\right)$ & $0,03 \mathrm{a}$ & $0,03 \mathrm{a}$ & 0,03 & 22,16 & $0,03 \mathrm{~b}$ & $0,04 \mathrm{a}$ & 0,04 & 12,93 \\
\hline PDMatriz $\left(\mathrm{m}^{3} \mathrm{~m}^{-3}\right)$ & $0,36 \mathrm{a}$ & $0,34 \mathrm{a}$ & 0,35 & 6,25 & $0,33 b$ & $0,35 a$ & 0,34 & 3,39 \\
\hline CAMatriz $\left(\mathrm{m}^{3} \mathrm{~m}^{-3}\right)$ & $0,17 \mathrm{a}$ & $0,18 \mathrm{a}$ & 0,18 & 15,19 & $0,17 b$ & $0,19 a$ & 0,18 & 11,28 \\
\hline $\operatorname{CAt}\left(\mathrm{m}^{3} \mathrm{~m}^{-3}\right)$ & $0,20 \mathrm{a}$ & $0,21 \mathrm{a}$ & 0,21 & 13,45 & $0,19 b$ & $0,22 \mathrm{a}$ & 0,21 & 10,43 \\
\hline $\mathrm{CC}\left(\mathrm{m}^{3} \mathrm{~m}^{-3}\right)$ & $0,19 \mathrm{a}$ & $0,16 b$ & 0,18 & 9,38 & $0,17 \mathrm{a}$ & $0,17 \mathrm{a}$ & 0,17 & 8,70 \\
\hline $\mathrm{CC} / \mathrm{Pt}$ & $0,49 \mathrm{a}$ & $0,43 b$ & 0,46 & 10,78 & $0,48 \mathrm{a}$ & $0,43 b$ & 0,46 & 9,23 \\
\hline $\mathrm{CAt} / \mathrm{Pt}$ & $0,51 b$ & $0,57 \mathrm{a}$ & 0,54 & 1,78 & $0,52 b$ & $0,57 \mathrm{a}$ & 0,54 & 9,23 \\
\hline
\end{tabular}

${ }^{(1)}$ Médias seguidas de letras iguais, na linha, não diferem entre si, a 5\% de probabilidade pelo teste Tukey. ${ }^{(2)}$ PDMacro, porosidade no domínio dos macroporos; PDMatriz, porosidade no domínio da matriz do solo; CAMatriz, capacidade de aeração da matriz do solo; CAt, capacidade de aeração total do solo; CC, conteúdo de água retido à capacidade de campo; CC/Pt, capacidade de armazenamento de água do solo, adimensional; e CAt/Pt, capacidade de armazenamento de ar do solo, adimensional. 


\section{Conclusões}

1. O pastejo em sistema de lotação contínua, com controle da taxa de lotação animal e manutenção da massa de forragem de coastcross, consorciado ou não com o amendoim forrageiro Arachis pintoi e adubado com nitrogênio, não compromete a qualidade física do Latossolo Vermelho distrófico.

2. A capacidade de armazenamento de água do solo é um indicador sensível para se avaliarem os efeitos da intensificação da utilização da pastagem sobre a qualidade física do solo.

\section{Referências}

BANZATTO, D.A.; KRONKA, S.N. Experimentação agrícola. 4.ed. Jaboticabal: Funep, 2006. 237p.

CORRÊA, L. de A.; CANTARELlA, H.; PRIMAVESI, A.C.; PRIMAVESI, O.; FREITAS, A.R. de; SILVA, A.G. de. Efeito de fontes e doses de nitrogênio na produção e qualidade da forragem de capim-coastcross. Revista Brasileira de Zootecnia, v.36, p.763-772, 2007.

EMBRAPA. Manual de métodos de análise de solo. 2.ed. Rio de Janeiro: Embrapa-CNPS, 1997. 212p. (Embrapa-CNPS. Documentos, 1).

EMBRAPA. Sistema brasileiro de classificação de solos. 2.ed. Rio de Janeiro: Embrapa Solos, 2006. 306p.

FIDALSKI, J.; AULER, P.A.M. Alterações químicas temporais nas faixas de adubação e entrelinhas do pomar, nutrição e produção de laranja após calagem superficial. Revista Brasileira de Ciência do Solo, v.32, p.689-696, 2008.

FIDALSKI, J.; TORMENA, C.A. Dinâmica da calagem superficial em um Latossolo Vermelho distrófico. Revista Brasileira de Ciência do Solo, v.29, p.235-247, 2005.

FIDALSKI, J.; TORMENA, C.A.; SILVA, A.P. da. Qualidade física do solo em pomar de laranjeira no Noroeste do Paraná com manejo da cobertura permanente na entrelinha. Revista Brasileira de Ciência do Solo, v.31, p.423-433, 2007.

GIAROLA, N.F.B.; TORMENA, C.A.; DUTRA, A.C. Degradação física de um Latossolo Vermelho utilizado para produção intensiva de forragem. Revista Brasileira de Ciência do Solo, v.31, p.863-873, 2007.

GRABLE, A.R.; SIEMER, E.G. Effects of bulk density, aggregate size, and soil water suction on oxygen diffusion, redox potentials and elongation of corn roots. Soil Science Society of America Journal, v.32, p.180-186, 1968.

GREENWOOD, K.L.; McKENZIE, B.M. Grazing effects on soil physical properties and the consequences for pastures: a review. Australian Journal of Experimental Agriculture, v.41, p.1231-1250, 2001.
IMHOFF, S.; SILVA, A.P. da; TORMENA, C.A. Aplicações da curva de resistência no controle da qualidade física de um solo sob pastagem. Pesquisa Agropecuária Brasileira, v.35, p.1493-1500, 2000.

LANZANOVA, M.E.; NICOLOSO, R. da S.; LOVATO, T.; ELTZ, F.L.F.; AMADO, T.J.C.; REINERT, D.J. Atributos físicos do solo em sistema de integração lavoura-pecuária sob plantio direto. Revista Brasileira de Ciência do Solo, v.31, p.1131-1140, 2007.

LEÃO, T.P.; SILVA, A.P. da; MACEDO, M.C.M.; IMHOFF, S.; EUCLIDES, V.P.B. Least limiting water range: a potential indicator of changes in near-surface soil physical quality after the conversion of Brazilian Savanna into pasture. Soil Tillage and Research, v.88, p.279-285, 2006.

LUGÃO, S.M.B.; RODRIGUES, L.R. de A.; ABRAHÃO, J.J. dos S.; MALHEIROS, E.B.; MORAIS, A. de. Acúmulo de forragem e eficiência de utilização do nitrogênio em pastagens de Panicum maximum Jacq. (acesso BRA-006998) adubadas com nitrogênio. Acta Scientiarum. Animal Sciences, v.25, p.371-379, 2003.

MACHADO, J.L.; TORMENA, C.A.; FIDALSKI, J.; SCAPIM, C.A. Inter-relações entre as propriedades físicas e os coeficientes da curva de retenção de água de um Latossolo sob diferentes sistemas de uso. Revista Brasileira de Ciência do Solo, v.32, p.495-502, 2008.

MARCHÃO, R.L.; BALBINO, L.C.; SILVA, E.M. da; SANTOS JUNIOR, J. de D.G. dos; SÁ, M.A.C. de; VILELA, L.; BECQUER, T. Qualidade física de um Latossolo Vermelho sob sistemas de integração lavoura-pecuária no Cerrado. Pesquisa Agropecuária Brasileira, v.42, p.873-882, 2007.

MOTT, G.O.; LUCAS, H.L. The design, conduct and interpretation of grazing trials on cultivated and improved pastures. In: International Grassland Congress, 6., 1952, Pennsylvania. Proceedings. Pennsylvania: State College Press, 1952. p.1380-1385.

MULLER, M.M.L.; GUIMARÃES, M. de F.; DESJARDINS, T.; MARTINS, P.F. da S. Degradação de pastagens na Região Amazônica: propriedades físicas do solo e crescimento de raízes. Pesquisa Agropecuária Brasileira, v.36, p.1409-1418, 2001.

OLIVEIRA, P.P.A.; TRIVELIN, P.C.O.; OLIVEIRA, W.S. Eficiência da fertilização nitrogenada com uréia $\left({ }^{15} \mathrm{~N}\right)$ em Brachiaria brizantha $\mathrm{cv}$. Marandu associada ao parcelamento de superfosfato simples e cloreto de potássio. Revista Brasileira de Ciência do Solo, v.27, p.613-620, 2003.

PACIULLO, D.S.C.; AROEIRA, L.J.M.; ALVIM, M.J.; CARVALHO, M.M. Características produtivas e qualitativas de pastagem de braquiária em monocultivo e consorciada com estilosantes. Pesquisa Agropecuária Brasileira, v.38, p.421-426, 2003.

REYNOLDS, W.D.; BOWMAN, B.T.; DRURY, C.F.; TAN, C.S.; LU, X. Indicators of good soil physical quality: density and storage parameters. Geoderma, v.110, p.131-146, 2002.

RIBEIRO, O.L. Produção animal e características da pastagem de coastcross consorciada com Arachis pintoi, 
com e sem nitrogênio. 2007. 71p. Dissertação (Mestrado) Universidade Estadual de Maringá, Maringá.

SARMENTO, P.; RODRIGUES, L.R. de A.; CRUZ, M.C.P. da; LUGÃO, S.M.B.; CAMPOS, F.P. de; CENTURION, J.F.; FERREIRA, M.E. Atributos químicos e físicos de um Argissolo cultivado com Panicum maximum Jacq. cv. IPR-86 Milênio, sob lotação rotacionada e adubado com nitrogênio. Revista Brasileira de Ciência do Solo, v.32, p.183-193, 2008.

SILVA, A.P. da; IMHOFF, S.; CORSI, M. Evaluation of soil compaction in an irrigated short-duration grazing system. Soil Tillage and Research, v.70, p.83-90, 2003.
SILVA, J.J. da; SALIBA, E. de O.S. Pastagens consorciadas: uma alternativa para sistemas extensivos e orgânicos. Veterinária e Zootecnia, v.14, p.8-18, 2007.

SKOPP, J.; JAWSON, M.D.; DORAN, J.W. Steady-state aerobic microbial activity as a function of soil water content. Soil Science Society of America Journal, v.54, p.1619-1625, 1990.

TWERDOFF, D.A.; CHANASYK, D.S.; MAPFUMO, E.; NAETH, M.A.; BARON, V.S. Impacts of forage grazing and cultivation on near-surface relative compaction. Canadian Journal of Soil Science, v.79, p.465-471, 1999.

Recebido em 13 de junho de 2008 e aprovado em 8 de outubro de 2008 